\title{
Effect of TheraCyte-encapsulated parathyroid cells on lumbar fusion in a rat model
}

\author{
Sung-Hsiung Chen $\cdot$ Shun-Chen Huang • \\ Chun-Chung Lui $\cdot$ Tzu-Ping Lin · \\ Fong-Fu Chou $\cdot$ Jih-Yang Ko
}

Received: 18 September 2011/Revised: 1 May 2012/ Accepted: 18 June 2012/Published online: 6 July 2012

(C) The Author(s) 2012. This article is published with open access at Springerlink.com

\begin{abstract}
Introduction Implantation of TheraCyte $4 \times 10^{6}$ live parathyroid cells can increase the bone marrow density of the spine of ovariectomized rats. There has been no published study examining the effect of such implantation on spinal fusion outcomes. The purpose of this study was to examine the effect of TheraCyte-encapsulated parathyroid cells on posterolateral lumbar fusions in a rat model.

Materials and methods Forty Sprague-Dawley rats underwent single-level, intertransverse process spinal fusions using iliac crest autograft. The rats were randomly assigned to two groups: Group 1 rats received sham operations on their necks (control; $N=20$ ); Group 2 rats were implanted with TheraCyte-encapsulated $4 \times 10^{6}$ live parathyroid cells into the subcutis of their necks (TheraCyte; $N=20$ ). Six weeks after surgery the rats were killed.
\end{abstract}

S.-H. Chen - T.-P. Lin · J.-Y. Ko

Department of Orthopaedic Surgery, Kaohsiung Chang Gung

Memorial Hospital, Chang Gung University College

of Medicine, Kaohsiung, Taiwan

S.-C. Huang

Department of Anatomic Pathology, Kaohsiung Chang Gung

Memorial Hospital, Chang Gung University College

of Medicine, Kaohsiung, Taiwan

C.-C. Lui

Department of Diagnostic Radiology, Kaohsiung Chang Gung

Memorial Hospital, Chang Gung University College

of Medicine, Kaohsiung, Taiwan

F.-F. Chou ( $\square)$

Department of General Surgery, Kaohsiung Chang Gung

Memorial Hospital, Chang Gung University College

of Medicine, \#123 Ta-Pei Rd., Niao-Sung Dist.,

Kaohsiung, Taiwan

e-mail: choulu@ms4.hinet.net; chensh@adm.cgmh.org.tw
Fusion was assessed by inspection, manual palpation, radiography, and histology. Blood was drawn to measure the serum levels of calcium, phosphorus, and intact parathyroid hormone (iPTH).

Results Based on manual palpation, the control group had a fusion rate of $33 \%(6 / 18)$ and the TheraCyte group had a fusion rate of $72 \%(13 / 18)(P=0.044)$. Histology confirmed the manual palpation results. Serum iPTH levels were significantly higher in the TheraCyte group compared with the control group $(P<0.05)$; neither serum calcium nor phosphorus levels were significantly different between the two groups.

Discussion This pilot animal study revealed that there were more fusions in rats that received TheraCyte-encapsulated $4 \times 10^{6}$ live parathyroid cells than in control rats without significant change in serum calcium or phosphorus concentrations. As with any animal study, the results may not extrapolate to a higher species. Further studies are needed to determine if these effects are clinically significant.

Keywords Animal models - TheraCyte parathyroid cells · Lumbar fusion

\section{Introduction}

It has long been believed that good therapeutic outcomes with regard to degenerative disease of the lumbar spine are achieved by fusion after posterior fusion [1]. Failure to achieve solid fusion may lead to loss of alignment, instability, pain, and potential neurologic injury. Augmentation with autologous bone graft is the current gold standard procedure to achieve lumbar solid fusion [2]. However, use of autograft is limited by supply and there is significant donor site morbidity [3]. Many attempts have been undertaken to 
minimize the need to harvest autograft and maximize the effect of autograft or bone graft alternatives. A potential alternative for facilitating fusion is the administration of systemic medication that has known anabolic effects on bone. Parathyroid hormone (PTH) is one such candidate protein. Daily injection appears to induce a net increase in bone formation [2-6], assist fracture healing [7-9], and facilitate bone formation and fusion rates in the rat posterolateral lumbar fusion model $[10,11]$. However, daily injection of PTH is inconvenient and troublesome. Another option is transplantation of parathyroid tissues, but the main obstacle with this option is immunological rejection $[12,13]$. We as well as others have found that using a microencapsulate of human parathyroid cells significantly increase PTH secretion in vitro and in rats without pharmacological immunosuppression [14-16]. Following the implantation of TheraCyte-encapsulated parathyroid cells in rats, we found that the parathyroid cells could survive and secrete intact PTH (iPTH) for up to 3 months [14]. No lymphocyte infiltration was found within the TheraCyte device. Implantation of TheraCyte $4 \times 10^{6}$ live parathyroid cells can function very well and increase bone marrow density (BMD) in the lumbar spine for up to 3 months or longer. There has been no published study examining its effect on spinal fusion outcomes. The purpose of this study is to examine the effect of TheraCyte-encapsulated parathyroid cells on posterolateral lumbar fusion in a rat model.

\section{Materials and methods}

Forty Sprague-Dawley rats approximately 10 weeks of age and 220-280 g in weight were selected for this study. Anesthesia was induced with ketamine and xylocaine intraperitoneally, and perioperative antibiotics were administered subcutaneously. The rats were placed in the prone position and prepared in standard surgical fashion. L4-L5 posterolateral fusions were performed $[17,18]$. The spine was approached (Wiltse approach) through a single midline skin incision and two paramedian fascial incisions. The spinal level was determined with reference to the iliac crests. After exposure, the transverse process was decorticated, bone graft was harvested from both iliac crests, and fascial incisions were made over the iliac crests. A rongeur was used to harvest approximately $0.1-0.2 \mathrm{cc}$ of morselized corticocancellous bone from both iliac crests. The wounds were irrigated, and the harvested graft was placed into the fusion levels. We put the grafts under the fascia of the paraspinal skeletal muscle after the fascia was opened. Then the fascia was sutured. So the graft would remain at the fusion site. At the same time, the rats were randomly assigned to one of two groups: Group 1 rats underwent sham operations on their necks (control group; $n=20$ ); Group 2 rats were implanted with TheraCyte-encapsulated $4 \times 10^{6}$ live parathyroid cells into the subcutis of their necks (TheraCyte group; $n=20$ ). The Animal Use and Care Committee of our hospital approved these procedures.

\section{Preparation of PTH cells [14]}

Parathyroid glands were obtained from patients who had undergone surgery for symptomatic secondary hyperparathyroidism. All parathyroid gland specimens were cut into pieces and collected in Roswell Park Memorial Institute (RPMI) solution (85\%), dimethyl sulfoxide (DMSO) (10\%), and fetal calf serum (5\%). After step-freezing to $-79^{\circ} \mathrm{C}$, specimens were stored in liquid nitrogen $\left(-197{ }^{\circ} \mathrm{C}\right)$. Written informed consent was obtained from all patients.

The parathyroid tissue was thawed in a $37{ }^{\circ} \mathrm{C}$ water bath, minced into small fragments in DMEM-f-12 medium (Sigma Chemical, St. Louis, MO, USA), and digested for $2 \mathrm{~h}$ at $37^{\circ} \mathrm{C}$ in media containing collagenase II $(1.2 \mathrm{mg} /$ $\mathrm{ml}$; Sigma Chemical). After centrifugation at $500 \mathrm{~g}$ and mechanical dispersion, the pellet was resuspended in complete growth medium (DMEM-F-12) supplemented with $5 \%$ calf serum, $1 \%$ Nutridoma-SP (Boehringer Mannheim, Germany), $100 \mathrm{U}$ penicillin/ml, $100 \mu \mathrm{g}$ of streptomycin/ml, $1 \mathrm{mM} \mathrm{CaCl}$ and $0.5 \mathrm{mM} \mathrm{MgCl}_{2}$, and the suspension was filtered through 60- and 150-mesh screens.

The viability of the detached cells (trypsin/0.06\% EDTA) was tested by the trypan blue method. A mixture of $1 \mu \mathrm{l}$ of cells (density of $4 \times 10^{5} / \mathrm{ml}$ ) and $5 \mu \mathrm{l}$ trypan blue was prepared, and then placed in a counting chamber to determine the viability ratio (live cells/live + dead cells).

TheraCyte implantable systems (Irvine, Calif.) were used for cell encapsulation. The parathyroid cells were passed through a 150-mesh screen, collected, and distributed, and then suspended in RPMI solution at a density of $4 \times 10^{6}$ live cells/ml for the TheraCyte group. Using the centrifugation loading method according to the user's manual (TheraCyte), the TheraCyte-encapsulated live parathyroid cells were implanted into the subcutaneous layer of the necks of the rats. The TheraCyte device consists of an inner membrane of polytetrafluoroethylene (PTFE) that is $30 \mu \mathrm{m}$ thick and has a $0.4-\mu \mathrm{m}$ pore size which prevents the entry of cells into the device, while allowing the entry of antibodies and compliment factors, and a laminated 15- $\mu \mathrm{m}$ thick PTFE outer membrane which has a 5 - $\mu \mathrm{m}$ pore size that allows improved biocompatibility and induced vascularization. For the final step, $4 \times 10^{6}$ cells in a volume of $1 \mathrm{ml}$ were loaded into the 4.5- $\mu$ l device (TheraCyte).

\section{Killing and analysis}

Six weeks after surgery, the lumbar spines were excised and the fusion masses were examined. After inspection, 
manual palpation testing of the L4-L5 segment was performed by three independent observers [17, 18]. Only levels graded as solid by at least two observers were considered to be fused. Posteroanterior radiographs were obtained for all specimens after the rats were killed. The radiographs were viewed and graded as fused or not fused. Representative specimens were fixed in $10 \%$ neutral formalin, decalcified, cut sagittally, then embedded in paraffin, and stained with hematoxylin and eosin for microscopic examination $[19,20]$. Blood was drawn at the time of implantation of the TheraCyte implantable system and during killing to measure calcium, phosphorus, and human iPTH levels.

\section{Statistical analysis}

Data were expressed as mean \pm standard deviation. Statistical analysis was performed using repeated measures of analysis of variance for iPTH, calcium, and phosphorus levels. Fisher's exact test (two-tailed) was used to determine if the proportion of rats judged as fused was significantly greater in the TheraCyte group relative to the control group. Comparison of trends in weight gain for the two groups was performed using the one-tailed Student's $t$ test. Significance was defined as $P<0.05$.

\section{Results}

Two rats expired due to anesthesia toxicity and two rats were excluded from the study due to deep wound infection. The final analysis included 18 rats in the control group and 18 rats in the TheraCyte group. The remaining rats tolerated the surgical procedure well and were ambulatory on the following postoperative days. A trend in weight gain was observed in the rats over time. The increase in body weight for the control and TheraCyte experimental groups was $36.2 \pm 18.1$ and $34.5 \pm 17.1 \mathrm{~g}$, respectively. However, at final examination, there was no significant difference in body weight between the two groups.

The explanted spines were assessed by manual palpation (Table 1). Only levels graded as solid by at least two

Table 1 Fusion rates (manual palpation data for the control and TheraCyte groups)

\begin{tabular}{lll}
\hline & Control (\%) & TheraCyte $(\%)$ \\
\hline Observer 1 & $7 / 18(39)$ & $14 / 18(78)$ \\
Observer 2 & $7 / 18(39)$ & $13 / 18(72)$ \\
Observer 3 & $6 / 18(33)$ & $11 / 18(61)$ \\
All* & $6 / 18(33)$ & $13 / 18(72)$ \\
\hline
\end{tabular}

* Fisher's exact test (two-tailed) was used to compare the two groups $(P=0.044)$
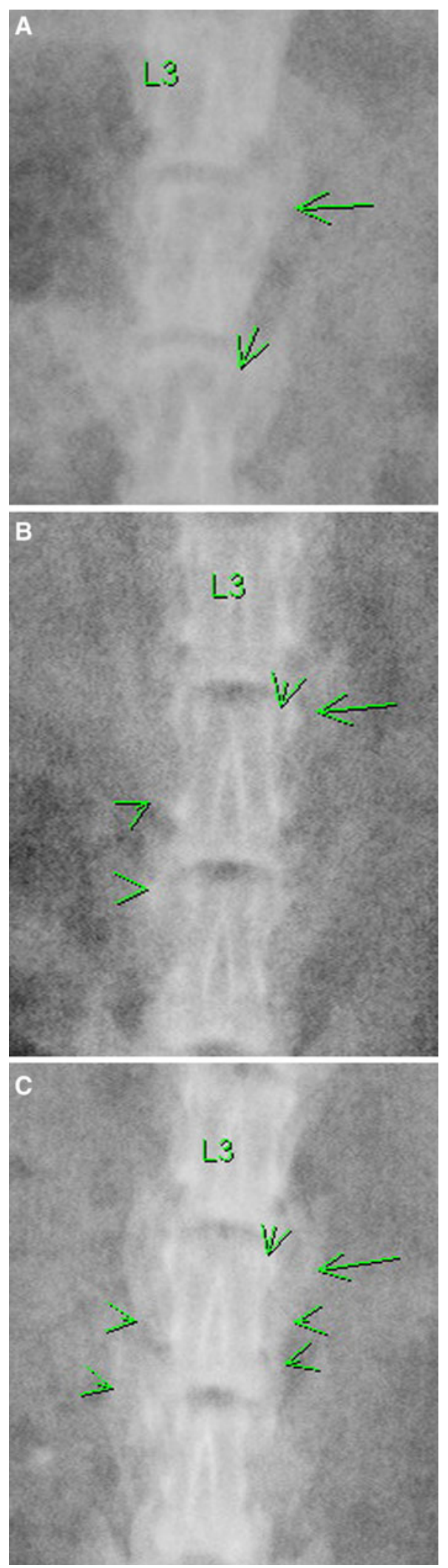

Fig. 1 The processes transversus (long arrow), facet joint (short arrow), fused bony graft (arrow head) of lumbar area are highlighted with arrows. Typical radiographs of a non-fusion, b partial fusion, and $\mathbf{c}$ good fusion are presented 

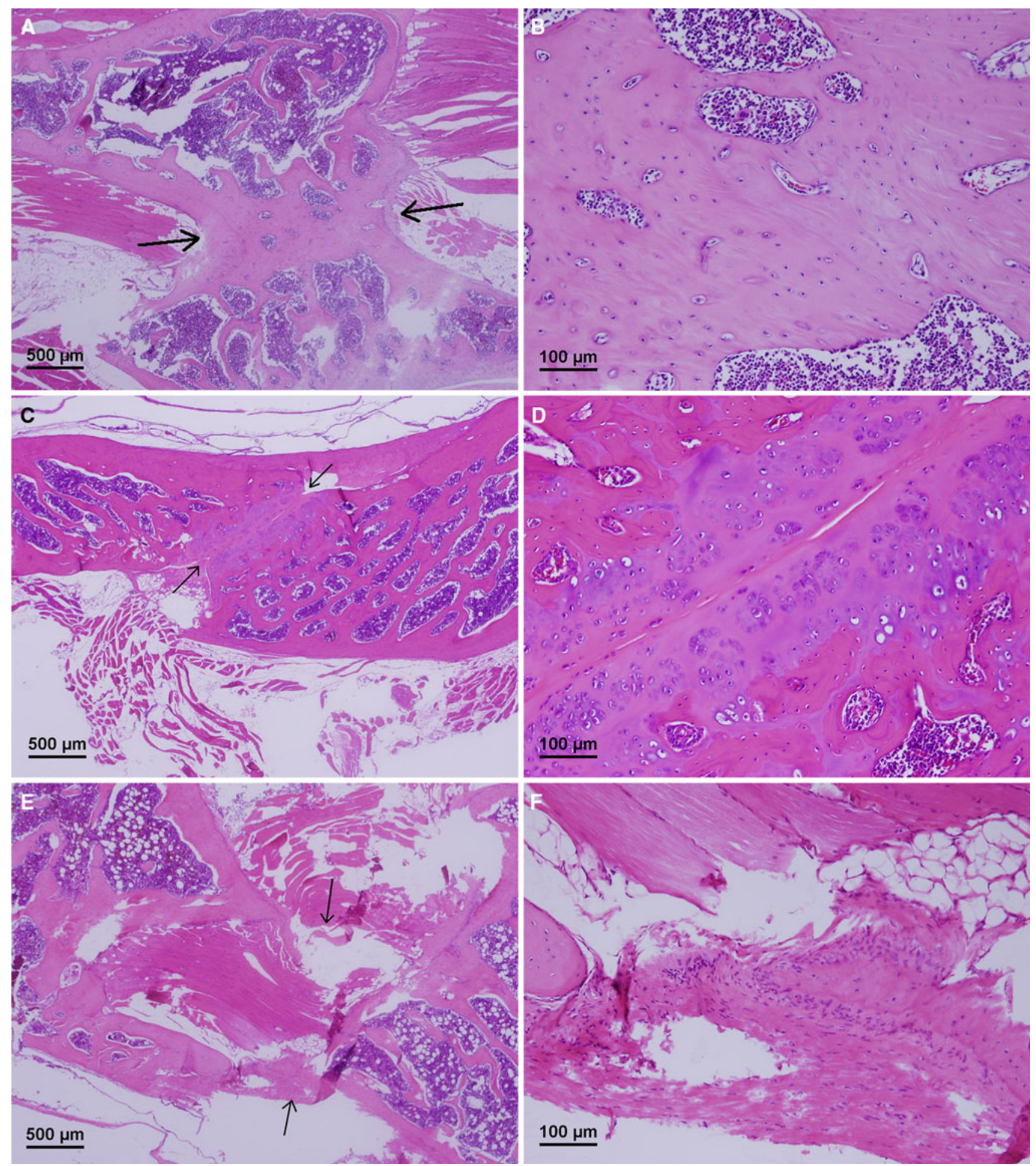

Fig. 2 The areas between grafted bony chip are highlighted with arrows. Bridging trabeculae (a) with new bone formation (b) or fibrous adhesion between bone graft chips (c and d) in the TheraCyte

group. Fibroadipose tissue and skeletal muscle separated bone graft chips in the control group (e and f). Hematoxylin and eosin

observers were considered to be fused. Fusion was found in 6 of 18 rats (33\%) in the control group and 13 of 18 rats $(72 \%)$ in the TheraCyte experimental group; the difference was statistically significant $(P=0.044)$. Assessment

of the evidence for bone fusion was difficult due to the radiopacity of the rat skeletal system (Fig. 1). The radiographic fusion rate for the control group was $11 \%(2 / 18)$ and for the TheraCyte group $50 \%(9 / 18)$. 
Table 2 Serum levels of calcium $(\mathrm{mg} / \mathrm{dl})$, phosphorus $(\mathrm{mg} / \mathrm{dl})$, and iPTH $(\mathrm{pg} / \mathrm{ml})$ at time of implantation and 6 weeks after TheraCyte implantation

\begin{tabular}{|c|c|c|c|c|c|c|}
\hline & \multicolumn{2}{|c|}{ Serum level of calcium* } & \multicolumn{2}{|c|}{ Serum levels of phosphorus** } & \multicolumn{2}{|c|}{ Serum levels of iPTH*** } \\
\hline & Time of implantation & 6 weeks & Time of implantation & 6 weeks & Time of implantation & 6 weeks \\
\hline Control & $10.3 \pm 0.56$ & $9.6 \pm 1.22$ & $5.3 \pm 0.35$ & $4.5 \pm 0.77$ & $5.45 \pm 0.99$ & $4.77 \pm 2.1$ \\
\hline TheraCyte & $10.2 \pm 0.55$ & $10.3 \pm 0.54$ & $5.2 \pm 0.845$ & $5.5 \pm 0.43$ & $5.10 \pm 1.98$ & $9.3 \pm 1.43$ \\
\hline
\end{tabular}

Values were obtained using repeated measures of analysis of variance. All data are presented as mean \pm standard deviation

$* P=0.118$

** $P=0.143$

*** $P<0.05$

Histology analysis revealed bridging trabeculae or fibrous adhesion bone graft chips in the fused specimens (Fig. 2a-d). In the non-fused specimens, the bony islands were widely separated by fibroadipose tissue and skeletal muscle without bridging trabeculae or fibrous adhesion between the graft chips (Fig. 2e, f). Overall, the results of histology analysis were consistent with those of manual palpation. Serum iPTH $(\mathrm{pg} / \mathrm{ml})$ levels were significantly higher in the TheraCyte group than in the control group $(P<0.05)$. However, there was no significant difference between the two groups in the level of serum calcium $(P=0.118)$ or phosphorus $(P=0.143)$ (Table 2$)$.

\section{Discussion}

Parathyroid hormone acts via PTH-1 receptors on osteoblasts and bone marrow stromal cells to induce osteoblastic bone formation [19, 21, 22]. Its anabolic effects on the skeleton have been well documented [23-25]. In animal studies, PTH has been shown to facilitate facture healing $[7,23]$ and increase the lumbar fusion rate $[10,11]$. Although effective in the treatment of osteoporosis, daily injection of PTH for a period of 1-2 years is required [8, 24 , 26]. However, because daily injection of PTH is inconvenient and troublesome, we used the implantation of parathyroid tissue. In our previous study [14], following implantation of TheraCyte-encapsulated $4 \times 10^{6}$ live parathyroid cells in rats, we found that the parathyroid cells can function very well and increase BMD in the lumbar spine. It was thus hypothesized that the implantation of TheraCyte-encapsulated parathyroid cells might enhance the bone formation in the settings of fracture, non-unions, and fusions. This animal study revealed more fusion in rats that received implantation of TheraCyte-encapsulated $4 \times 10^{6}$ live parathyroid cells than in those rats that did not (72 vs. $33 \%$ ). Serum levels of calcium and phosphorus were not significantly different between the two groups. It is presumed that the kidneys of the rats were functioning normally and could keep serum calcium and phosphorus levels within the normal range. Higher serum level of iPTH in the TheraCyte group indicated good viability of the implanted cells while the level was not high enough to cause abnormal calcium concentration.

In the rats in our study, body weight at 6 weeks after implantation was higher than that at baseline. However, the differences between the two groups were not significant and therefore the effect of body weight could be ignored.

Multiple means of fusion assessment have been used in animal studies and fusion rates have differed among the methods of analysis. Manual palpation has been proven to be consistent and predictive of precise multidirectional biomechanical testing in previous studies [18]. While histology provides solid information about bone formation and quality, it is possible that a gross error may miss the bridging bone. Thus, we used manual palpation as the standard to determine whether or not fusion had occurred in this animal model [17, 18]. Radiographic examination has been found to be notoriously poor for determining the presence or absence of fusion in rats due to their small size $[17,18,27,28]$. In this animal study, we also had difficulty correlating manual palpation results with radiographic findings. In correlation with histology, it appeared that the fibrous adhesion between cartilage was felt as solid fusion on manual palpation while appearing as a gap between implanted bony chips on radiography.

Posterolateral intertransverse process fusion is the common type of surgical fusion performed in the lumbar spine. The reported rate of non-union has ranged from 5 to $35 \%[2,29]$. This fusion rate can be improved by systemic medications [10,11] or bone graft extenders, enhancer, and substitutes [29]. In this rat posterolateral spinal fusion model using the autologous bone graft the TheraCyteencapsulated live parathyroid cells significantly enhanced posterolateral fusion success. Although the results are encouraging, care must be taken when extrapolating these results to human lumbar fusion. As with any animal study, not all results seen in lower species are reproducible in higher species. Further studies are needed to determine the clinical significance. In conclusion, this pilot animal study 
revealed more fusions in rats that received TheraCyteencapsulated $4 \times 10^{6}$ live parathyroid cells without causing high serum calcium or low phosphorus concentrations.

\section{Conflict of interest None.}

Open Access This article is distributed under the terms of the Creative Commons Attribution License which permits any use, distribution, and reproduction in any medium, provided the original author(s) and the source are credited.

\section{References}

1. Tokuhashi Y, Ajiro Y, Umezawa N (2008) Follow-up of patients with delayed union after posterior fusion with pedicle screw fixation. Spine 33:786-791

2. Steinmann JC, Herkowitz HN (1992) Pseudarthrosis of the spine. Clin Orthop Relat Res 284:80-90

3. Gupta AR, Shah NR, Patel TC, Grauer JN (2001) Perioperative and long-term complications of iliac crest bone graft harvesting for spinal surgery: a quantitative review of the literature. Int Med J 8:163-166

4. Hock JM, Gera I (1992) Effects of continuous and intermittent administration and inhibition of resorption on the anabolic response of the bone to parathyroid hormone. J Bone Miner Res 7:65-72

5. Kobayashi S, Amano J, Minoru F, Kazuhiko A, Shingu K, Itoh K, Hama Y, Takemoto M, Imasaki T, Teramato A, Abe K (2000) Microcapsulated parathyroid tissue in vitro. Biomed Pharmacother 54(Suppl 1):66S-68S

6. Tam CS, Heersche JN, Murray TM, Parsons JA (1982) Parthyroid hormone stimulates the bone apposition rate independently of its resorptive action: differential effects of intermittent and continuous administration. Endocrinology 110:506-512

7. Holzer G, Majeska RJ, Lundy MW, Hartke JR, Einhorn TA (1999) Parathryoid hormone enhances fracture healing: a preliminary report. Clin Orthop Relat Res 366:258-263

8. Neer RM, Arnaud CD, Zanchetta JR, Prince R, Gaich GA, Reginster JY, Hodsman AB, Eriksen EF, Ish-Shalom S, Genant HK, Wang O, Mitlak BH (2001) Effect of parathyroid hormone (1-34) on fractures and bone mineral density in postmenopausal women with osteoporosis. N Engl J Med 344:1431-1441

9. Skripitz R, Andreassen TT, Aspenberg P (2000) Strong effect of PTH (1-34) on regenerating bone-a time sequence study in rats. Acta Orthop Scand 71:619-624

10. Lawrence JP, Ennis F, White AP, Magit D, Polzhofer G, Drespe I, Troiano NW, Grauer JN (2006) Effect of daily parathyroid hormone (1-34) on lumbar fusion in a rat model. Spine $\mathbf{J}$ 6:385-390

11. O'Loughlin PF, Cunninghan ME, Bukata SV, Tomin E, Poynton AR, Doty S, Sama AA, Lane JM (2009) Parathyroid hormone (1-34) augments spinal fusion, fusion mass volume, and fusion mass quality in a rabbit spinal fusion model. Spine 34:121-130

12. Timms S, Hamelmann W, Otto C, Gassel AM, Etzel M, Ulrichs K, Thiede A, Timmermann W (2001) Influence of donor MHC Class I antigen expression on graft survival after rat parathyroid allotransplantation. Langenbecks Arch Surg 386:430-433
13. Timm S, Otto C, Begrich D, Illert B, Hamelmann W, Ulrichs K, Thiede A, Timmermann W (2003) Short-term immunosuppression after rat parathyroid allotransplantation. Microsurgery 23:503-507

14. Chou CC, Huang SC, Chen SS, Wang PW, Huang PH, Lu KY (2006) Treatment of osteoporosis with TheraCyte-encapsulated parathyroid cells: a study in a rat model. Osteoporos Int 17:936-941

15. Gaumann A, Laudes M, Jacob B, Pommersheim R, Laue C, Vogt W, Schrezenmeir J (2001) Xenotransplantation of parathyroids in rats using barium-alginate and polyacrylic acid multilayer microcapsules. Exp Toxicol Pathol 53:35-43

16. Picariello L, Benvenuti S, Recenti R, Formigli L, Falchetti A, Morelli A, Masi L, Tonelli F, Cicchi P, Brandi ML (2001) Microencapsulation of human parathyroid cells: a "in vitro" study. J Surg Res 96:81-89

17. Bomback DA, Grauer JN, Lugo R, Troiaro NW, Patel TC, Friedlaender GE (2004) Comparison of posterolateral lumbar fusion rates of Grafton Putty and OP-1 Putty in an athymic rat model. Spine 29:1612-1617

18. Grauer JN, Bomback DA, Lugo R, Troiano NW, Patel TC, Friedlaender GE (2004) Posterolateral lumbar fusions in athymic rats: characterization of a model. Spine J 4:281-286

19. Horwitz MJ, Tedesco MB, Gundberg C, Garcia-Ocana A, Stewart AF (2003) Short-term, high-dose parathyroid hormone-related protein as a skeletal anabolic agent for the treatment of postmenopausal osteoporosis. J Clin Endocrinol Metab 88:569-575

20. Kacena MA, Troiano NW, Wilson KW, Coady CE, Horowitz MC (2004) Evaluation of two different methylmethacrylate processing, infiltration, and embedding techniques on the histological, histochemical and immunohistochemical analysis of murine bone specimens. J Histotechnol 27:119-130

21. Dempster DW, Cosman F, Parisien M, Shen N, Lindsay R (1993) Anabolic actions of parathyroid hormone on bone. Endocr Rev 14:690-709

22. Rosen CJ, Bilezikian JP (2001) Clinical Review 123: anabolic therapy for osteoporosis. J Clin Endocrinol Metab 86:957-967

23. Andreassen TT, Fledelius C, Ejersted C, Oxlund H (2001) Increases in callus formation and mechanical strength of healing: fractures in old rats treated with parathyroid hormone. Acta Orthop Scand 72:304-307

24. Hodsman AB, Hanley DA, Ettinger MP, Bolognese MA, Fox J, Metcalfe AJ, Lindsay R (2003) Efficacy and safety of human parathyroid hormone-(1-84) in increasing bone mineral density in postmenopausal osteoporosis. J Clin Endocrinol Metab 88:5212-5220

25. McClung M (2004) Parathyroid hormone for the treatment of osteoporosis. Obstet Gynecol Surv 59:826-832

26. Tashjian AH Jr, Chabner BA (2002) Commentary on clinical safety of recombinant human parathyroid hormone 1-34 in the treatment of osteoporosis in men and postmenopausal women. J Bone Miner Res 17:1151-1161

27. Boden SD, Schimandle JH, Hutton WC (1995) An experimental lumbar intertransverse process spinal fusion model: radiographic, histologic and biomechanical healing characteristics. Spine 20:412-420

28. Grauer JN, Patel TC, Erulkar JS, Troiano NW, Panjabi MM, Friedlaender GE (2001) 2000 Young Investigator Research Award winner. Evaluation of OP-1 as a graft substitute for intertransverse process lumbar fusion. Spine 26:127-133

29. Morone MA, Boden SD (1998) Experimental posterolateral lumbar spinal fusion with a demineralized bone matrix gel. Spine 23:159-167 